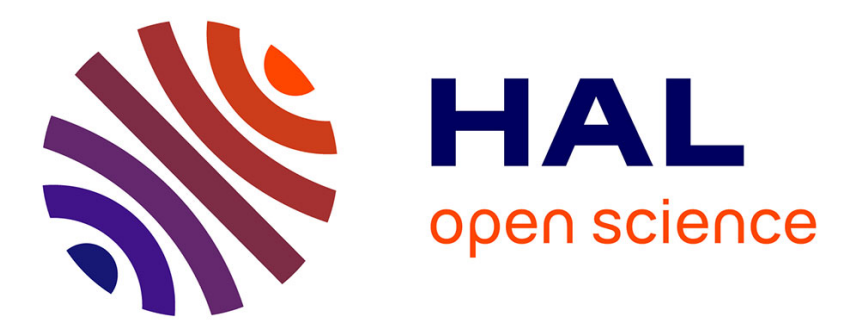

\title{
Performance Enhancement of Tilt-Body Micro Air Vehicle by Use of Orthotropic Laminated Proprotors
}

Fazila Mohd Zawawi, Peng Lv, Sebastien Prothin, Joseph Morlier, Emmanuel Bénard, Jean-Marc Moschetta

\section{- To cite this version:}

Fazila Mohd Zawawi, Peng Lv, Sebastien Prothin, Joseph Morlier, Emmanuel Bénard, et al.. Performance Enhancement of Tilt-Body Micro Air Vehicle by Use of Orthotropic Laminated Proprotors. Applied Mechanics and Materials, 2016, vol. 819, pp. 585-590. 10.4028/www.scientific.net/AMM.819.585 . hal-01661764

\section{HAL Id: hal-01661764 https://hal.science/hal-01661764}

Submitted on 12 Dec 2017

HAL is a multi-disciplinary open access archive for the deposit and dissemination of scientific research documents, whether they are published or not. The documents may come from teaching and research institutions in France or abroad, or from public or private research centers.
L'archive ouverte pluridisciplinaire HAL, est destinée au dépôt et à la diffusion de documents scientifiques de niveau recherche, publiés ou non, émanant des établissements d'enseignement et de recherche français ou étrangers, des laboratoires publics ou privés. 


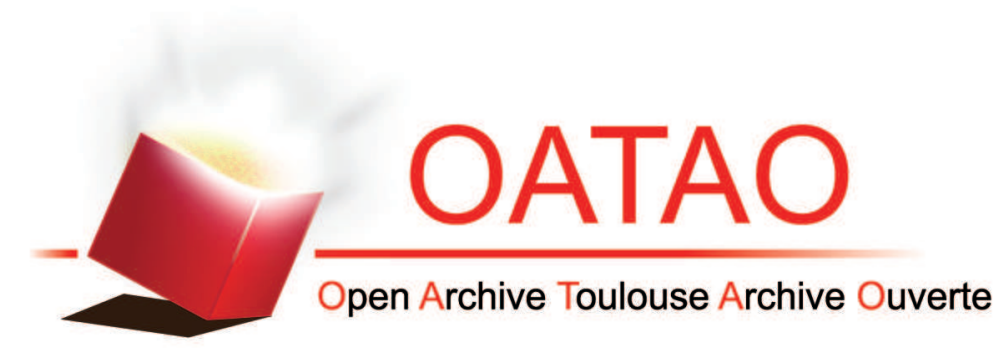

\section{Open Archive Toulouse Archive Ouverte (OATAO)}

OATAO is an open access repository that collects the work of some Toulouse researchers and makes it freely available over the web where possible.

This is an author's version published in: https://oatao.univ-toulouse.fr/18188

Official URL : http://dx.doi.org/10.4028/www.scientific.net/AMM.819.585

\section{To cite this version :}

Mohd Zawawi, Fazila and Lv, Peng and Prothin, Sebastien and Morlier, Joseph and Bénard, Emmanuel and Moschetta, Jean-Marc Performance Enhancement of Tilt-Body Micro Air Vehicle by Use of Orthotropic Laminated Proprotors. (2016) Applied Mechanics and Materials, vol. 819. pp. 585-590. ISSN 1660-9336

Any correspondence concerning this service should be sent to the repository administrator: tech-oatao@listes-diff.inp-toulouse.fr 


\title{
Performance Enhancement of Tilt-Body Micro Air Vehicle by Use of Orthotropic Laminated Proprotors
}

\author{
MOHD ZAWAWI Fazila ${ }^{1, a}$, LV Peng, ${ }^{2, b}$, PROTHIN Sebastien ${ }^{2, c}$, \\ MORLIER Joseph ${ }^{2,3, d}$, BENARD Emmanuel ${ }^{2, \mathrm{e}}$ \\ and MOSCHETTA Jean-Marc ${ }^{2, f}$
}

\author{
${ }^{1}$ Faculty of Mechanical Engineering, Universiti Teknologi Malaysia (UTM), 81310 Skudai, Malaysia \\ ${ }^{2}$ Departement de Aérodynamique, Enérgetic et Propulsion (DAEP), Institut Supérieur de \\ l'Aéronautique et de l'Espace (ISAE), 31055 Toulouse, France \\ ${ }^{3}$ Institut Clément Ader (ICA), 31055 Toulouse, France \\ afazila@mail.fkm.utm.my, bpeng.Iv@isae.fr, csebastien.prothin@isae.fr, dJoseph.Morlier@isae.fr, \\ eEmmanuel.Benard@isae.fr, fJean-Marc.Moschetta@isae.fr
}

Keywords: Tilt-body Aircraft, Micro-Air Vehicles, Flexible Blade, Orthotropic Laminated Composite, Blade-Element-Momentum Theory, Optimum Propeller/Rotor Blades, Passively-Adaptive Blades.

\begin{abstract}
A passive twist control is considered as an adaptive way to maximize the overall efficiency of a proprotor developed for convertible Micro Air Vehicles (MAV). In this paper, adaptation of the proprotor geometry in accordance to flight configurations is achieved by induced twist generated by the inherent structural coupling effect in anisotropic composite material and centrifugal force emanating from the tip load. Beam Finite Element Model based on Rotating Timoshenko Theory is used to predict structural loads, while Blade Element Momentum Theory is employed to predict the aerodynamic performance of adaptive proprotor as applied on Micro Air Vehicles (MAV). The iterative process of combination of aerodynamic model and structural model is used to compute the steady-state deformation of the flexible laminated proprotor blade due aerodynamic loads. Finally, the optimal design of lamina blade material is carried out to investigate the potential of flexible blade in the proprotor performance enhancement.
\end{abstract}

\section{Introduction}

Tilt-body micro-air-vehicles (TB-MAV) have been regarded over the last decade as promising candidates for convertible multi-tasking configuration as they intrinsically combine both vertical and horizontal flight capabilities. TB-MAV not only can sustain vertical flight over the target for clear image/video information transmission or gathering but also capable of fast horizontal flight for the sake of fast forward movement. While TB-MAVs concept is very promising, it confronts with significant challenges. Certainly it is necessary to ensure the rotorblades that are able to work well over the complete flight of the vehicle: from static or low-speed vertical flight through high-speed forward flight. The substantial variation in the vehicle dynamics between these two flight configurations directs to a considerably different in the both aerodynamics of the vehicle and rotorblades. From the aerodynamic requirement, high thrust is required by the proprotor to balance the weight during hovering while small thrust is required during cruise to compensate the drag, suggests in general different blade pitch and twist angle. This phenomenon requires the use of hybrid active pitch control and passive twist control system to offer highest possible efficiency at both flight modes. For example, from the study done by Nixon in 1988 [1] found that the optimum blade twist for hover is $20^{\circ}$ while it is above $45^{\circ}$ for the airplane mode. Improvement in the power requirement of $6 \%$ was reported in both hover and airplane modes with respect to a compromise design of $36^{\circ}$ linear twist. Active pitch control concept nonetheless is inapplicable or almost unrealistic for small-sized rotor with blade thickness of approximately $2 \mathrm{~mm}$ due to its complexity and the unavailability of control devices in the small size range, and requires non-mechanical control system to be used. Therefore, the focus in this paper 

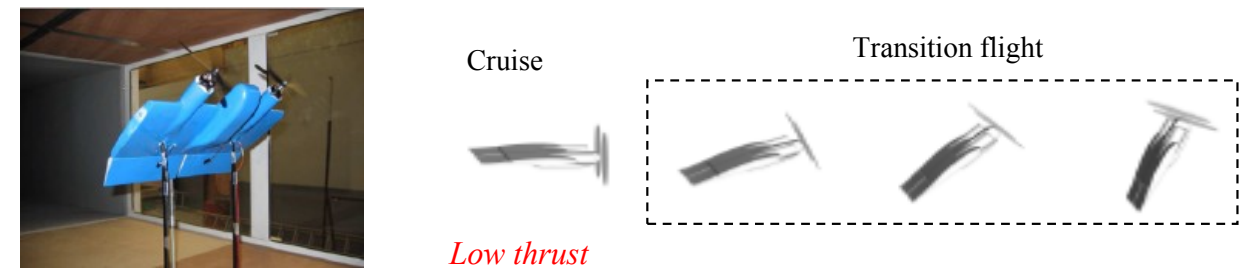

Hover

Fig. 1: MAVion (DAEP, ISAE); Dimensions: $400 \mathrm{~mm}$ x $220 \mathrm{~mm}$

would be the passively adaptive blade concept where the blade changes are adjusted by the structural deformation through aerodynamic loadings, where it can promise simple, light-weight and economic mechanism in terms of maintenance cost when compared with actively-adaptive blade concept. In the context of MAV proprotor performance enhancement, composite materials especially laminated composite plates, is chosen to be used for its light weight and its controllability of the structural properties through changing the fiber orientation angles and the number of plies and selecting proper composite materials. Hence, the idea behind the passively-adaptive blade design is to carry out the optimization of orthotropic lamina blade stacking sequence for tilt-body micro-air-vehicles (TB-MAV) proprotors in hover and forward flight configurations.

\section{Design Requirement and Optimization Problem}

The TB-MAV developed at ISAE, namely MAVion as shown in Fig. 1 was used as a baseline in the design process. Since two proprotors were used in the MAVion in order to control the yaw direction, the $T_{r e q}$ at cruise flight was constrained by the half of MAVion's drag at the target cruising velocity $\mathrm{V}=16 \mathrm{~m} / \mathrm{s}$. Whereas for the hover flight, $T_{r e q}$ was constrained by the half of the MAVion's weight of 350 grams. The design requirement for MAVion proprotor at each flight configuration is shown in Table 1 . However, an additional positive $3 \%$ of thrust for both flight cases is allowed in the equality of constraint of thrust.

Table 1: Design requirements for MAVion's proprotor ([3], [4])

\begin{tabular}{lcc}
\hline \hline Flight configuration & Velocity, $\mathrm{V}(\mathrm{m} / \mathrm{s})$ & Required thrust, $T_{r e q}$ \\
\hline Hover & 0 & $1.7 \mathrm{~N}(\leq+3 \%)$ \\
Cruise & 16 & $0.32 \mathrm{~N}(\leq+3 \%)$ \\
\hline \hline
\end{tabular}

The form of the rigid proprotor blades optimization problem concept are according to the minimization of the total power $P_{\text {total }}$ of the overall flight whose the definition is stated as follows:

$$
\text { Minimize }: P_{\text {total } / \text { mission }}=\alpha_{f} P_{\text {total }(\text { hover })}+\left(1-\alpha_{f}\right) P_{\text {total(cruise })}
$$

where $\alpha_{f}$ is the coefficient of flight composition. The optimal design of the blade is constrained by the required thrust in the respective hover and cruise flight configurations.

$$
\begin{aligned}
& \text { Subject to : } T_{r e q(h)}=\text { Weight } \quad \text { (Rotor case) } \\
& \text { : } T_{\text {req }(c)}=\mathrm{Drag}=\mathrm{f}(\mathrm{V}) \quad \text { (Propeller case) }
\end{aligned}
$$

\section{Optimal Performance of Rigid-Bladed Proprotor}

Before the optimization of stacking sequence of orthotropic lamina blade was carried out, the optimal geometry in terms of hub pitch $\Delta \beta_{0}$ and twist angle distribution $\beta(r)$ of proprotor in both hover and cruise is computed. The selected optimal geometry is chosen based upon the blade that can produce 
maximum of combined hovering efficiency, characterized by Figure of Merit $F M$ and propulsive efficiency $\eta_{\text {prop }}$. The optimal rigid blade geometry is significant to ensure that the flexible blade able to enhance the proprotor performance through a small torsion deformation, can also be explicitly said that how much still the optimized rigid proprotor can enhanced its performance by use of flexible blade. The proprotor having hub pitch angle $\Delta \beta_{0}$ between $10^{\circ}$ to $60^{\circ}$ and linear built-in twist $B I T$ between $-10^{\circ}$ to $-50^{\circ}$ were analyzed by using FPROP proprotor analysis program whose program is developed to include the nonlinear effect at $M A V$ Reynolds number region $(\operatorname{Re}<70,000)[2]$. The detailed equation systems used in FPROP can be found in [2].

The results as seen in Fig. 2 can be grouped into 3 which are (i) acceptable compromised design for proprotor; (ii) Only stall in cruise (negative CT(cruise)) and (iii) Stall in both cruise (negative thrust coefficient $C_{T}$ in cruise $-C_{T \text { (cruise) }}$ ) and hover (negative $-C_{T(\text { hover })}$ ). To note that a negative thrust will yield a complex number in FM. The FM of the group 'stall in hover' plots only account the real part meanwhile the imaginary part is ignored. Finally, it is found that the maximum efficiency that can be achieved by fixed rigid proprotor in hover and cruise are $0.31(F M)$ and $70 \%\left(\eta_{\text {prop }}\right)$ which produced by the proprotor blade having BIT $35^{\circ}$ and $\Delta \beta_{0} 60^{\circ}$.

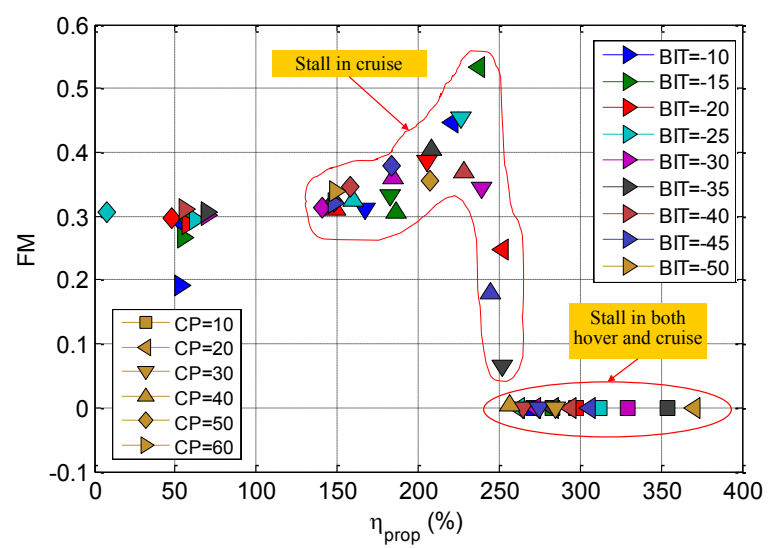

Fig. 2: Pareto designs and selected optimal geometry for fixed rigid proprotor

\section{Flexible Blade Design}

Design Strategy As opposed to rigid proprotor, the performance of a flexible proprotor cannot simply be expressed as a function of $R P M$ or $V$ due to differences in dimensional load, which will induce different blade deformations, and hence change the aerodynamic performance. By design, the geometry of a flexible proprotor, notably the $\beta(r)$ at radius $\mathrm{r}$, changes as a function of $V$ and $R P M$ due to aerodynamic or tip body loadinduced blade deformations. Therefore, $\beta(r)$ can vary radially such that $\alpha_{\text {opt }}$ remains near the optimal values at each radial position for a range of $V$ and $R P M$. By exploiting the bending-twisting coupling effects of composite proprotors caused by aerodynamic loads and extension-twist coupling effects caused by centrifugal force which is emanating from the blade and tip body, the flexible proprotor can enhance performance through variable passive pitch adaptation. Therefore, it can be said that

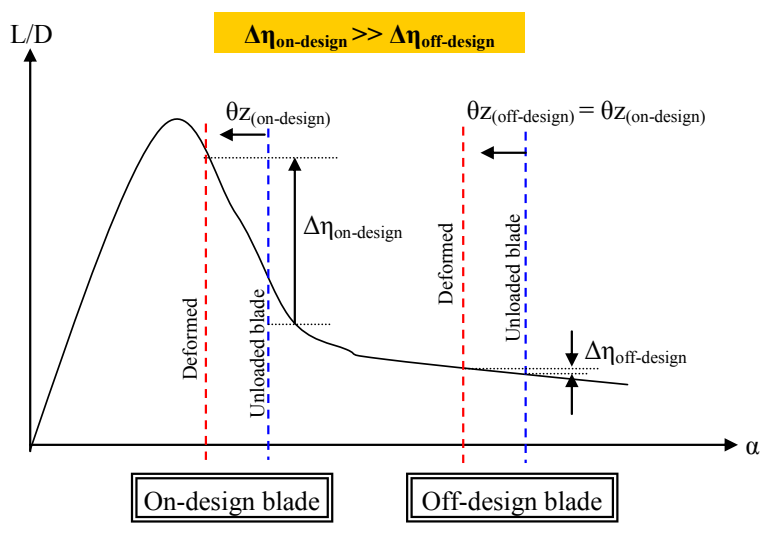

Fig. 3: Potential performance enhancement in the on-design flexible blade and off-design flexible blade through the similar magnitude of induced torsion the most important strategy in designing the material and geometry of the flexible proprotor blades, especially when the design is subjected to the thrust constraint, is that the chosen unloaded blade geometry should be as close as the geometry corresponding to optimal condition for both hover and forward flight. With a same amount of induced torsion, the on-design blade can offer pronounced enhancement in proprotor performance compared 
to the off-design proprotor, as described in Fig. 3. It is worth to note that there is a possibility that the off-design flexible blade even worser the performance of the proprotor, makes the blade geometry design based on rigid blade significant in the initial process of flexible proprotor design.

Optimization Result and Analysis For analysis, the orthotropic lamina rectangular blade was chosen. The upper orientation of the orthotropic lamina is ranged between $0^{\circ}$ to $180^{\circ}$. The effect within this range on torsion deformation and their corresponding aerodynamic loadings changes was investigated and compared to each other. The fiber orientation, number of fiber, and blade thickness were kept constant when designing both cruise and hover blades.

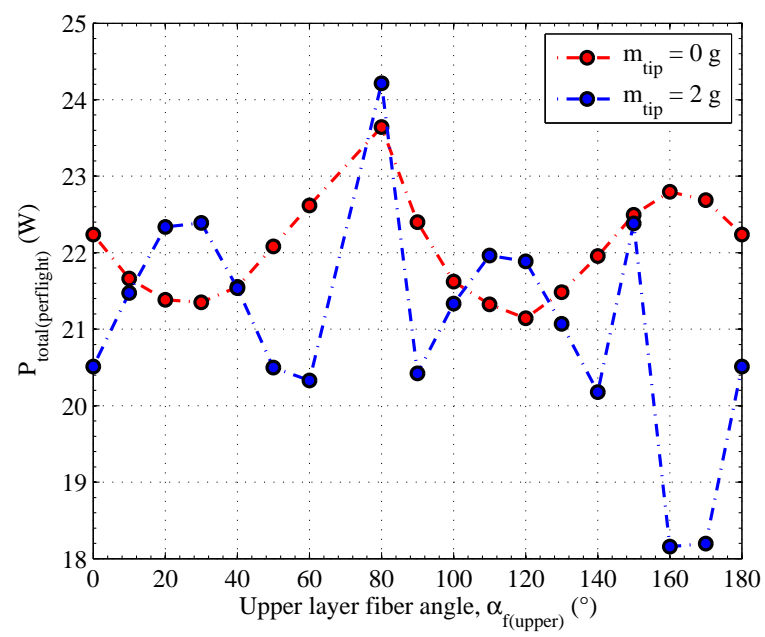

(a) Overall flight

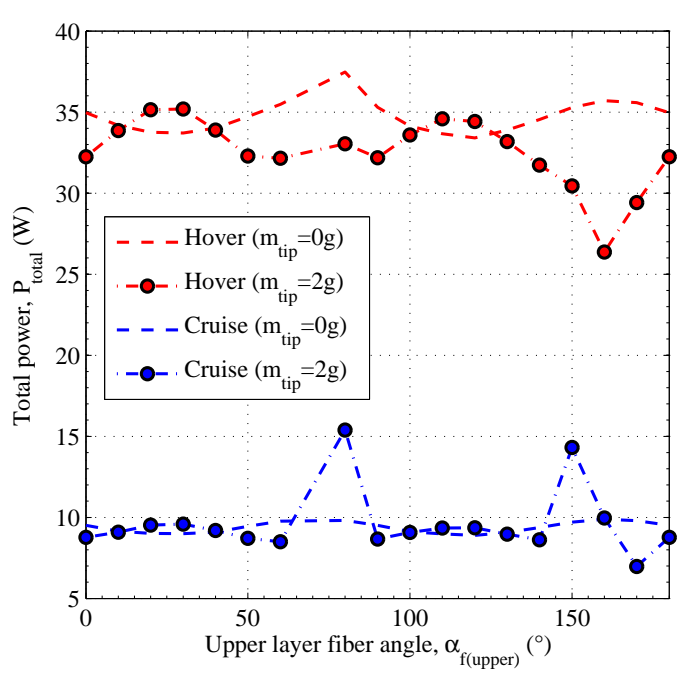

(b) Hover and Cruise

Fig. 4: Change in total power in (a) overall flight and (b) hover and cruise as a function angle of fiber of 4-ply asymmetric $\left[\alpha_{f(\text { upper })} / \alpha_{f(\text { upper })} / \alpha_{f(\text { upper })}+90 / \alpha_{f(\text { upper })}+90\right]$ laminated carbon fiber for unloaded-tip blade $(\mathrm{m}=0 \mathrm{~g})$ and loaded-tip blade $(\mathrm{m}=2 \mathrm{~g})$.

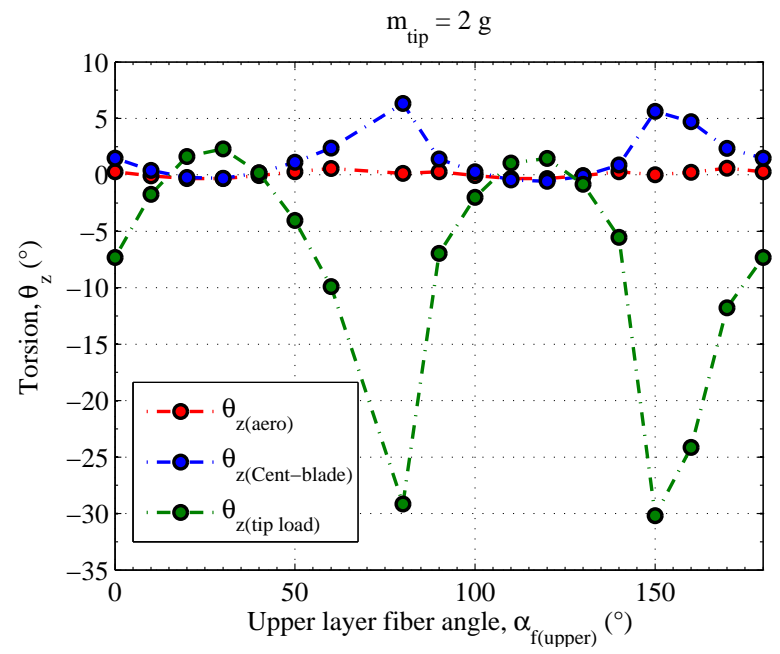

(a) Cruise

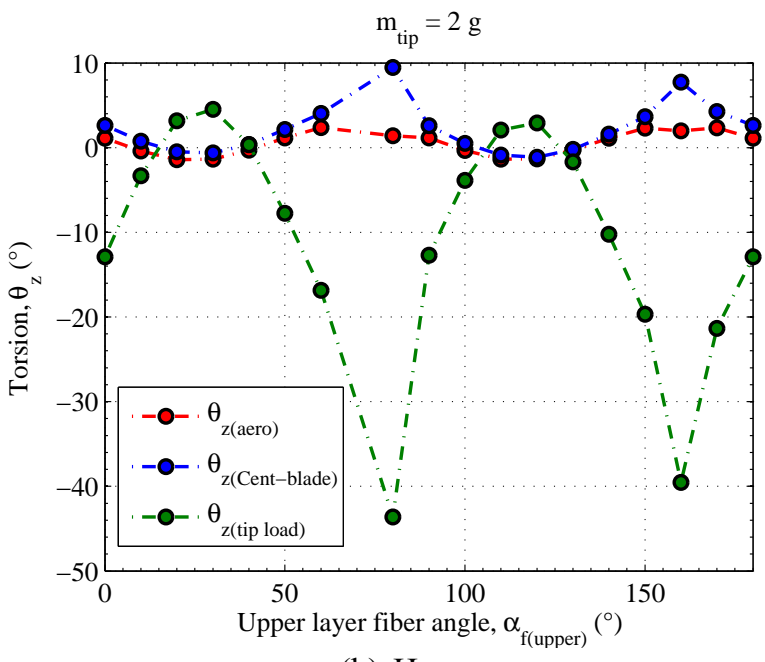

(b) Hover

Fig. 5: Torsion corresponding to required thrust in (a) cruise and (b) hover induced by the different sources (aerodynamic loading, blade body loading); $m_{t i p}=2$ gram

Amongst the designed proprotors, optimized rigid fixed proprotor $\left(B I T-35^{\circ}, \Delta \beta_{0} 60^{\circ}\right)$ was found to be the most less efficient. Replacing the rigid blade in the optimized fixed proprotor with the flexible anisotropic laminate blade $\left(S S_{\text {opt }}=\left[-20^{\circ} /-20^{\circ} / 70^{\circ} / 70^{\circ}\right]\right)$ created a reduction in total power by the amount of $0.92 \mathrm{~W}$ or $10.3 \%$ in hover flight and by $3.75 \mathrm{~W}$ or $14.3 \%$ in cruise flight. The reduction in total power prolonged the endurance time in the respective flight modes by 1.36 minutes and 5.57 
minutes. No reduction in $P_{\text {total }}$ was observed in the proprotor with other configurations of initial blade geometry and stacking sequence of the orthotropic lamina blade in both cruise and hover. Also, insufficient torsion deformation is observed in proprotor with no tip load at any fiber configurations. From Fig. 5 we found that the torsion at optimal material $\left(S S_{o p t}=\left[-20^{\circ} /-20^{\circ} / 70^{\circ} / 70^{\circ}\right]\right)$ in both hover and cruise are generated by the torsional moment created by the tip load.

To identify whether or not the optimized proprotor; rigid blade and flexible blade can manage to show enhancement in the performance, their performance are compared with the performance of the conventional propellers commonly used for MAVion which are APC $8 \times 6$ and Graupner $8 \times 6$. The comparison results are shown in Table 2.

Table 2: Operation point at hover and cruise condition

\begin{tabular}{lccccc}
\hline \hline Propeller & & RPM & $\eta_{\text {prop }}$ or $F M$ & $P_{\text {total }}(\mathrm{W})$ & $P_{\text {total } / \text { mission }}(\mathrm{W})$ \\
\hline \multirow{2}{*}{ APC $8 \times 6$} & Cruise & 5950 & $0.45 \%$ & 15.80 & \multirow{2}{*}{20.36} \\
& Hover & 6611 & 0.361 & 24.911 & \\
\hline \multirow{2}{*}{ Graupner $8 \times 6$} & Cruise & 5930 & $0.44 \%$ & 13.33 & \multirow{2}{*}{17.24} \\
\hline Optimal rigid proprotor & Hover & 5159 & 0.44 & 21.154 & \multirow{2}{*}{20.03} \\
Airfoil: flat-plate $(t / c=3.5 \%)$ & Cruise & 3885 & $0.67 \%$ & 7.89 & \multirow{2}{*}{17.69} \\
\hline Optimal flexible proprotor & Cruise & 3676 & 0.31 & 32.17 & \\
SS $=\left[-20 \% /-20^{\circ} / 70^{\circ} / 70^{\circ}\right]$ & Hover & 4950 & 0.35 & 28.42 & \\
\hline \hline
\end{tabular}

According to the comparison result, the optimal flexible proprotor can reduce the total power consumption by the amount of $2.34 \mathrm{~W}$ which is about $13.22 \%$ reduction when it is compared with the optimal rigid proprotor. By the $2.34 \mathrm{~W}$ reduction in total power, it increases time endurance by 3.2 minutes. When comparing with the best conventional propellers/rotors (Graupner $8 \times 6$ ), the optimized flexible proprotors improve significantly performace in cruise which is about $91.24 \%$. Between the optimized proprotor, the flexible blade improves performance in $P_{\text {total }}$ reduction by $13.2 \%$ in hover.

\section{Conclusion}

The optimization of material for $T B-M A V$ proprotor blade made of laminated composite material is presented. Flexible laminated blade is found to be able to improve the fixed rigid-bladed propotor through efficient and correct optimization. The role of load affixed to the blade tip is found to be highly significant in generating sufficient torsion deformation for ensuring proprotor performance enhancement. 


\section{References}

[1] W. Mark Nixon. Improvements to tilt rotor performance through passive blade twist control (Technical Momerandum 100583, NASA, April 1988).

[2] F. Mohd-Zawawi, P. Lv, S. Prothin, J. Morlier and J. M. Moschetta, Study of a flexible UAV proprotor, Int. Journal of Engineering Systems Modelling and Simulation, Vol. 6, Nos. 3/4 (2014), p. 149-161.

[3] F. Mohd-Zawawi, J. Morlier, G. Grondin and JM. Moschetta, Design of Optimum Torsionally Flexible PropRotors for Tilt-Body MAVs, Applied Mechanics and Materials, Vol. 225 (2012) p. 281-286.

[4] M. Itasse, JM. Moschetta, Numerical and Experimental Analysis of the Wing-propeller Interaction for a Tilt-Wing Micro Air Vehicle, Journal of Aircraft, Vol. 225 (2012) p. 281-286. 